\title{
SUGGESTED CHANGES IN FOREST SCHOOL COURSES
}

Alan R. Fenwick

$\Lambda \mathrm{S}$ a result of the current lack of demand for graduates of forest schools, resulting from the general industrial depression, greater interest is being taken in forestry education than would otherwise be the case.

Disregarding the depression, except as a temporary demand factor, it must be admitted that as certain fields in which specific types of forestry knowledge may now be applied have become fairly clearly outlined, present consideration of adjustment in existing school courses to meet the definite demand in these fields is justified.

Upon examination it is found that the policy of our forest schools has been to train students in the fundamentals of forestry science and at the same time to endeavour to give them a broad education in related subjects. The instruments and material selected for both these kinds of instruction have been taken from various sources according to their illustrative value, precedence naturally being given to Canadian sources when equal or nearly equal value obtains. This policy is in strict accordance with the highest principles of University education.

Deviation from the general policy has taken the form of imparting in. formation to students which may be of use in application to the specific problems likely to be encountered following graduation, which tendency is in line with the educational practice in other university courses.

The extent to which deviation from the pure university system is justified in forest school education in Canada to-day in the form of specialization, is the focus of the discussion which is taking place at present.

The unadulterated university system does not aim to turn out a finished product but presupposes that opportunity will be afforded after graduation for the further training of men in the field of endeavour in which they may be engaged until they have attained the degree of efficiency desired.

Employing agencies naturally would like to have the product as nearly finished as possible so that high early returns may be obtained, and each makes an appeal to the forest schools for specialization in training in their particular field.

This presents a difficult problem to the forest schools. Here is a definite demand for a half dozen different types of forestry specialists. The schools would like to supply that demand if possible, although they consider that each type should have the broad training essential to a well educated man and a training in the fundamentals of forestry science. 
Two practical alternative solutions to this problem are-

1. Division of the course into two or more parts, permitting of specialization in each part.

2. Additions to the present uniform course.

\section{DIVISION OF THE COURSE}

Since a five or six part division of the course is not feasible, one is lead to a consideration of the practicability of division into two parts, each of which includes a group of more or less closely related subjects. Another alternative which may be classed under this head is the acceptance of graduates of other faculties by the forest schools with the object of adding certain forestry knowledge to that training which they have already acquired.

\section{ADDITIONS TO THE UNIFORM COURSE}

Two alternatives are presented under this classification-

1. Lengthening of the course by one or two years to permit of additional specialized studies.

2. Modification of the present four year course to permit of additional specialized studies by,-

(a) Eliminating certain of the existing subjects.

(b) Shortening certain of the existing subjects by elimination and condensation of material content.

(c) A combination of (a) and (b).

Before proceeding further it should be noted that the stimulus for the present discussion has arisen out of an appeal for better equipment on the part of forest school graduates in the form of "applied" knowledge or information. This is but one of the three component parts of the school course, the other two being "fundamental scientific forestry training," and "broad education" in related subjects as noted previously. Since this is the case four questions should be asked-.

1. Should more time be devoted to imparting this type of "applied" information than at present, and how much?

2. Should either of the other two fields of education be entered and how far?

3. What information should be imparted?

4. How this information may best be imparted.

The first two questions involve pedagogical policy to such a degree that the answer must be left almost entirely to the educationalists concerned, due consideration being given to the intensity of the demand on the part of the employing agencies. These agencies should have a greater part in supplying the answer for the third question as they undoubtedly know what they want. The fourth question is one which is closely related to the third and can only 
be worked out through close co-operation between the schools and the employing agencies.

At the present time the most insistent appeal for special "applied" information comes from one of the employing agencies, namely, the woods divisions of the pulp and paper companies. The demand from this source specifies fairly clearly what the knowledge requirement is in addition to forestry knowledge. It is for woods utilization knowledge on the following subjects,--

1. Engineering.

(1) Structural-construction, strength of materials, etc.

(2) Internal combustion engines-operation, utility, etc.

(3) Surveying--specific field problems, draughting.

(4) Hydraulics-storage, rate of flow, pressures, etc.

(5) Engineering mathematics-relating to above.

2. Business.

(1) Accounting and accounting analysis.

(2) Material and labour statistics, etc.

(3) Contract law, liens, etc.

(4) Applied economics.

3. Logging (applied).

Systems, organization, contracting, labour, cruising, appraisal, felling, bucking, skidding, scaling, road hauling, loading, dumping, driving, rail-hauling, equipment, power, construction (simple), commissariat.

4. "Administration"-

Government relations, regulations, public relations, tenure, ("ownership"), dues, rentals, markets, milling, etc.

The large scale operations conducted by pulp and paper companies and the long term considerations involved call for a much higher type of organization than would obtain under smaller operation and shorter term conditions. The only apparent advantage in employing foresters on these operations rather than "practical woodsmen"-intelligence being considered equal for purposes of argument-is that the former are equipped in a more or less degree with the "scientific forestry" and related "broad educational" and basic engineering as well as the business and miscellaneous economic knowledge to which reference has been made previously. This advantage is counteracted at the outset to some extent by the greater experience of the "practical woodsmen."

While recognizing that a definite demand for this type of forestry specialist actually does exist, forestry educationalists are very careful in reorganizing school curricula lest the "applied information" part of the course become top

The term "applied" herein is meant to denote mechanical, instrumental vehicular characteristics. 
heavy with this particular branch of utilization, as similar appeals will undoubtedly come sooner or later from other employing agencies such as protection, surveying, reforestation and research services. Also this might involve the crowding of the other legitimate branches of education too far out of the picture resulting in a lowering of the standard of the whole course.

In this connection it is my opinion that the "applied information" branch of forest school education is perhaps encroaching too far in function upon the other two branches of the course. This is a question of policy which should be investigated and recognition given to the fact that the applied information type of subjects is different than the others. One point of difference between "applied science" and "pure science" subjects other than that which is implied by these terms is in "degree of development." For example, utilization, like radio, is a going concern, somewhat faulty in operation but offering possibilities for refinement. Silviculture in Canada is like television, being still in the laboratory stage, but offering possibilities, for future application.

Descriptions of logging operations typical of the region in which a particular forest school is situated and to which it is related should form the basis of the logging course of that school. Sufficient detail should be given to enable the students to gain an adequate working knowledge of these actual operations, and stress should be placed on the progress which is being made by means of the application of sound business practice through costs analysis; use of engineering principles in construction, operation and examination; and forestry science in the determination of cutting practice.

Such information, to be completely intelligible, should include costs data, progress reports, and maps, charts and plans with descriptions. Certain of this material including the finer quantitative and dimensional detail should not be included in the lecture notes except when essential to clarity of general description but should be distributed to students in the form of blueprints and mimeograph sheets.

Several complete descriptions of different operations in the same field should be compared throughout for the purpose of illustrating how either differences in operating policies or physical conditions may alter practice.

The foregoing treatment would not only be conducive to greater time economy, clarity and practical usefulness, but also to receptivity, through increased interest.

After a general treatment of typical pulpwood operations with particular attention being paid to "logging" as previously outlined under "operators" requirements; separate sections of the course should deal with engineering, business and administration. The treatment should cover only the basic principles, systems, and closely related facts pertaining to pulpwood logging practice. The knowledge of engineering mathematics required for such a study 
should be given in this course and should be confined to absolutely necessary details.

oration of the engineering faculty could incorporate the necessary material in his lectures. This should not be difficult and a very useful course might be worked out. The business and administrative sections could be built up in the same way.

The great importance of the pulp and paper industry as a utilization agency in Canada and the excellent opportunity which is offered for practical investigation into the possibilities of applying the principles of forestry in pulpwood operations lends considerable weight to present appeals for educational adjustment.

Efforts to bring about economical treatment of our forest resources will lead to the application of silvicultural methods in such a manner as economic circumstances will permit. The results of trial and error methods in crude practice at the one end will be supplemented by the application of pure research results at the other in determining the form of the operating procedure of the future.

If this be true, those engaged in all lines of governmental and industrial forestry activity should keep abreast of the developments in actual utilization.

Therefore, forest schools, while keeping strictly within the bounds of their function as university educational bodies, should lay the basic foundation of utilization knowledge on which their graduates might lay the bricks which they mould from more intensive study and experience.

May I digress slightly for a moment to state that a description of woods operations does not paint the whole picture in that the governments have a decided interest in that which is taking place in utilization, which interest though closely paralleling that of the operators is not identical. This part of the picture should be brought out in greater relief by more clear cut description. This idea may be carried still further in that the principle involved may be applied to advantage in the teaching of subjects concerned with the other forestry activities in which the fields have been outlined and the trends indicated.

I believe that it is the concensus of opinion among foresters that existing school curricula are admirably organized and well balanced and do not consider that radical changes such as the division of the present courses into special courses or the addition of years to the uniform courses to permit of further special study, are justified in order that the more reasonable de. mands of the present day be met.

As complete a knowledge as is obtainable in almost every subject in the present curricula is essential to a well educated forester regardless of how he may be engaged after graduation and division of the courses would simply mean subtraction of some of this knowledge. 
If it be impossible to obtain the services of engineering professors for the engineering branch of such a course the utilization professor with the collab-

Taking for granted that it be within the scope and function of a university forest school to include certain of the material which has been suggested for study, modification of the existing courses is advisable rather than division into special courses or lengthening the uniform courses to permit of further specialized study.

With regard to lengthening the courses for particular study, it seems to me that in doing this the field of post-graduate work is entered. This should not take place. A few post-graduate university courses might be organized to advantage but the major share of the burden must be borne by the employing agencies and the individual graduates themselves. Such responsibility should be recognized.

Upon analysis of the suggestions and criticisms of those who advocate radical changes in the school curricula it is found that there is little complaint with respect to the organization of the present curricula but rather with the content of the material in certain subjects, the organization of this material and the system of presenting it. "Divisionists" would substitute certain new material for that which they consider less essential, but why do they select whole subjects for substitution rather than certain of the material in the subjects in which they are interested?

I suggest that the logical procedure would be to re-organize the utilization subjects and certain of the other subjects in the "applied" field in such a way that the most useful of the new material suggested may be incorporated at the least expense of the old.

As time must be made to permit of this, certain of the material in these subjects would have to be condensed, others would have to receive less stress and still others might even have to be eliminated. A factor which decreases the difficulties of re-organization of subject material considerably is that a great deal of the new material is already present in the old subjects in some form. It appears to me then, that in the efforts to encompass a broad field in these studies, parts of the subjects which have but illustrative and general informational value are dealt with in too great detail at the expense of more useful material.

A narrowing of the field of the study of fundamental forestry principles or of closely related educational principles is not advocated but a narrowing of the field of the study of that material which may be usefully applied by the graduate forester in the region in which the school is situated is advisable 